\title{
DURABILITY OF CRYSTALLINE PHASE IN CONCRETE MICROSTRUCTURE MODIFIED BY THE MINERAL POWDERS: EVALUATION BY NANOINDENTATION TESTS
}

\author{
MAGDALENA RAJCZAKOWSKA, DARIUSZ ŁYDŻBA \\ Wrocław University of Science and Technology, Faculty of Civil Engineering, Wrocław, Poland, \\ e-mail: magdalena.rajczakowska@pwr.edu.pl (corresponding author)
}

\begin{abstract}
This paper presents the nanoindentation investigation of the evolution of concrete microstructure modified by the Internal Crystallization Technology mineral powders. The samples under study were retrieved from a fragment of a circular concrete lining of the vertical mine shaft at a depth of approximately $1,000 \mathrm{~m}$. Due to the aggressive environment and exposure to contaminated water, the internal surface of the structure was deteriorated, decreasing its strength significantly. The mineral powders were applied directly on the surface lining. The specimens were investigated one month, three months and one year after the application of the aforementioned substance in order to verify the time dependence of the strengthening processes and durability of the crystalline phase. The microstructural changes of concrete were assessed with the use of nanoindentation technique. The testing procedure involved including the previously cut specimens in the epoxy resin and grinding and polishing in order to reduce the surface roughness. As a result of the nanoindentation tests the hardness as well as Young's modulus of the material were evaluated. The results were then compared and statistically analyzed. As a consequence, the disintegration time of the crystalline network in the pores of concrete was identified.
\end{abstract}

Key words: nanoindentation, concrete, Internal Crystallization Technology, microstructure, durability

\section{INTRODUCTION}

Internal Crystallization Technology (ICT), one of the popular concrete strengthening methods, has been some kind of a mystery for several years. Producers of this innovation advertise their products as a very effective way of making concrete structure waterproof and often, in addition, improving its mechanical parameters. On the contrary to the concrete admixtures such as plasticizers or water reducers added directly to the concrete mix during preparation, the ICT in a form of a mineral powder can be applied on the mature concrete and it does not reduce the porosity of the material in a conventional way. Chemical composition of these substances allows them to react, in the presence of water, with non-hydrated elements of the cement matrix. As a consequence of their properties, ICT powders initiate crystalline formation in the pores of concrete. The crystalline phase produced is said to be non-soluble and relatively durable, depending on the type of ICT, making it possible "to tighten" the structure of concrete.
Despite their common application in civil engineering, there has not been objective and thorough study regarding the Internal Crystallization Technology. The only confirmation of its potential beneficial influence on the microstructural properties of concrete comes from the research conducted by the commercial resellers. The effectiveness and durability of the crystalline network in the pores of concrete, particularly subjected to chemically aggressive environment, is still questionable, ambiguous and requires objective examination. Moreover, as the waterproof effect is easier to understand, change in mechanical properties due to the presence of crystals in the pores is difficult to imagine. Therefore, in this article the evolution of concrete microstructure strengthened with ICT as well as the disintegration time of the crystalline network in the pores have been analyzed.

Concrete samples under investigation were retrieved from the fragment of a circular concrete lining of a vertical mine shaft at a depth of approximately $1,000 \mathrm{~m}$. Due to the aggressive environment and exposure to contaminated water, the surface of the structure was deteriorated, decreasing its strength 
significantly. Due to the high costs of a necessary repair of the lining with the traditional engineering methods, the Internal Crystallization Technology mineral powder was chosen as a potential solution to the existing problem. The cores were extracted one month, three months and one year after the application of the aforementioned substance in order to verify the time dependence of the strengthening processes and durability of the crystalline network. The microstructural changes in concrete were assessed with the use of nanoindentation technique. The testing procedure involved including the previously cut specimens in the epoxy resin and grinding and polishing in order to reduce the surface roughness. As a result of the nanoindentation tests the hardness as well as Young's modulus of the material were evaluated. The results were then compared and statistically analyzed. As a consequence, the disintegration time of the crystalline network in the pores of concrete was identified.

The article is constructed as follows. In Section 2, the principles of the nanoindentation technique are presented. The Olivier and Pharr method is described and the formulas for hardness and Young's modulus provided. The sample preparation procedures are described in Section 3. In Section 4, the results of the nanoindentation tests are demonstrated. Histograms as well statistical measures of hardness and Young's modulus are shown for the concrete, namely one month, three months and one year after the mineral powder application, respectively. The time effect on the strengthened concrete is investigated based on the comparative analysis of the results. The durability of the crystalline network is assessed. Summary ends the paper.

\section{PRINCIPLES OF NANOINDENTATION}

As material science started expanding and scientists became interested in the micromechanical behaviour of materials looking for the link to the macroscopic response, new laboratory tools needed to be developed. One of those tools is nanoindentation - a technique which brought traditional indentation methods of determining hardness of bulk materials to the scale of a single crystal (Syed Asif and Pethica, 1997). The principles of the nanoindentation first appeared in the publication of Doerner and Nix in 1986 (Doerner and Nix, 1986), however the technique that is used now has its origin in the publication of Oliver and Pharr from 1992 regarding the measurement of the mechanical properties of thin films (Pharr and Oliver, 1992). In the next years, Oliver and Pharr tried to improve their method by investigating the influence of different phenomena on the outcome of the tests, resulting in the refinement of the methodology in 2004 (Pharr and Oliver, 2004). Nanoindentation finds application in different research areas. Originally developed for thin metal films (Pharr and Oliver, 1992), later it became useful in biological sciences, i.e., determination of human bone mechanical properties at micro and nano scale (Rho et al., (1997, 2002); Fan et al., 2002). Recently, construction materials have also been studied by means of nanoindentation tests. Krakowiak performed a multiscale analysis of mechanical properties of clay brick (Krakowiak, 2011; Krakowiak et al, 2011). Bobko in his doctoral dissertation (2008) dealt with the link between mineral composition and mechanical properties of shale. Nanoindentation technique coupled with microscopy analysis was applied by Nežerka et al. (2015) to investigate ancient mortars. Ulm and his science group published a handful of papers on the mechanical properties of different composites in nano scale, developing statistical tool for the analysis of the results, i.e., grid indentation combined with the deconvolution technique (Constantinides et al., 2006; Ulm et al., 2007). This method gives a possibility to determine mechanical parameters of inhomogeneous material's components by analyzing the histograms of the hardness and Young's modulus measured by the indenter. Nevertheless, concrete became lately the most extensively studied building material with the use of nanoindentation as it is one of the most popular and common structural components. Therefore, there is an obvious need to understand the processes that occur in concrete at the micro and nano scale in order to be able to modify its properties and produce a more effective and durable material. In 2008, Sorelli et al. studied the behaviour of ultra-high performance concrete by means of nanoindentation (Sorelli et al., 2008). Vandamme applied nanoindentation to investigate concrete creep as it gives a significantly decreased testing time advantage (Vandamme, 2008). One of the crucial phenomena in concrete, i.e., Interfacial Transition Zone, was also examined with the use of nanoindentation method (Xiao et al., 2013). Modification of the concrete mix composition and its influence on the micromechanical behaviour of concrete was also tested (Mondal et al., 2010; Zadeh and Bobko, 2013). Tarefder and Faisal studied the aging of concrete (Tarefder and Faisal, 2013), whereas Němeček investigated size effect in nanoindentation of cement paste (Němeček et al., 


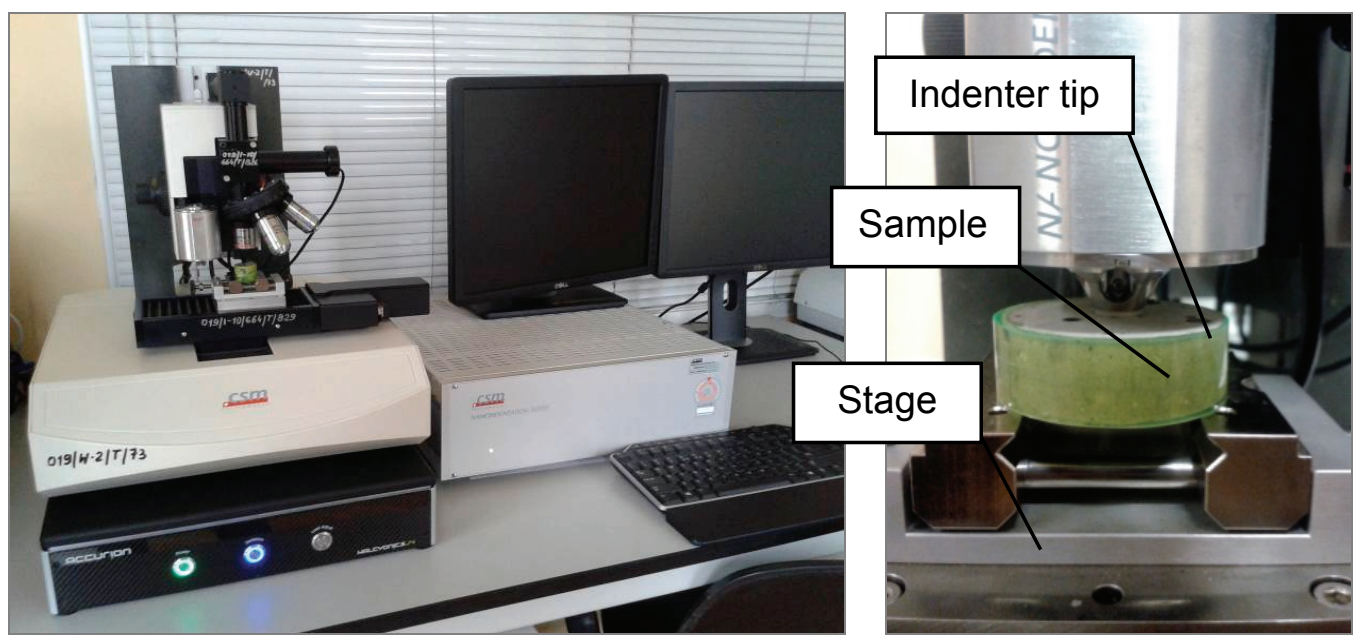

Fig. 1. Nanoindenter

2005). Despite a considerable number of publications regarding nanoindentation of concrete, there are still areas which have not been covered yet.

The nanoindentation test involves embedding of a hard diamond tip of a specified shape (e.g., conical, pyramid) into the material. Firstly, the load is being increased with a predefined rate until the maximum limit value, which depends on, e.g., the type of material, scale of measurement, properties under study, etc. This process is followed by the unloading phase. The depth of the indentation $h$ as well as the loading force $P$ are being registered providing the $P-h$ curve as a result of the test. Material behaviour can be assumed to be purely elastic during the unloading phase, therefore the slope of the aforementioned unloading curve may be used for the calculation of its elastic properties. The theoretical background of the indentation is related to Boussinesq's stress and displacement solution of an elastic half-space loaded by a rigid axisymmetric indenter (Boussinesq, 1885). If the linear, isotropic, elastic material is considered, the use of elastic solution for a flat cylindrical punch results in the following formula for the unloading curve (Constantinides et al., 2003)

$$
\frac{d P}{d h}=c^{*} \sqrt{A} E^{*}
$$

where $c^{*}=2 / \sqrt{\pi}, A$ depicts the contact area, and $E^{*}$ is given by the following relation

$$
\frac{1}{E^{*}}=\frac{1-v^{2}}{E_{I T}}+\frac{1-v_{i n}^{2}}{E_{\text {in }}}
$$

where $E_{i n}$ and $v_{i n}, E_{I T}$ and $v$ are Young's modulus and Poisson ratio of the indenter (for the diamond tip - $1000 \mathrm{GPa}, 0.07$ ) and material under study (Poisson ratio assumed is equal to 0.3 in this study), respectively (Constantinides et al., 2003). Equation (1) has been derived with as assumption of indenter to be of a smooth solid of revolution shape. The Berkovich indenter (a four-sided pyramidal cone) applied in this study does not verify this condition. Existing huge experimental data in the literature (see, for instance, Constantinides et al., 2003) confirms, however, applicability of formula (1) for the Berkovich indenter as well (Constantinides et al., 2003). The hardness of the material is determined according to the following formula (Constantinides et al., 2003)

$$
H_{I T}=\frac{P_{\max }}{A_{\max }}
$$

where $P_{\max }$ is the maximum load and $A_{\max }$ is the maximum imprint area. The calculation of the $A_{\max }$ is performed by the indenters software with the iterative method taking into account the sink-in and pileup phenomena being the results of the plastic behaviour of the material. In Fig. 1, a nanoindenter CSM TTX-NHT applied in this study is demonstrated. Table 1 lists major parameters of the device.

Table 1. Nanoindenter parameters

\begin{tabular}{|l|c|}
\hline \multicolumn{1}{|c|}{ Maximum load } & $500 \mathrm{mN}$ \\
\hline Minimal load & $40 \mu \mathrm{N}$ \\
\hline Maximum imprint depth & $200 \mu \mathrm{m}$ \\
\hline Minimal registerable depth & $0.04 \mathrm{~nm}$ \\
\hline
\end{tabular}

\section{SAMPLE PREPARATION}

From the extracted cores the smaller samples were cut for the nanoindentation tests. Each of the speci- 
mens had dimensions of $2.5 \times 2.5 \times 0.5 \mathrm{~cm}$ (Fig. $2 b$ ). In total, they covered around $7.5 \mathrm{~cm}$ distance from the surface of the concrete lining where the crystalline technology mineral powder was applied.

After cutting, the samples were included in resin in order to fill the pores of concrete, which is an obligatory procedure in order to be able to polish the surface of the material. The resin strengthens the brittle material and eliminates the possibility of the artifacts occurring during the sample preparation, e.g., cracking. Struers CitoVac vacuum machine was used (Fig. 2a). Each sample was placed in a special mold. Specific proportions of the epoxy resin, dye and hardener were measured and after accurate mixing of the ingredients the sample was filled with the mixture under vacuum. As a result, flat cylinders were acquired, which were ready for the polishing procedure (Fig. 2c).

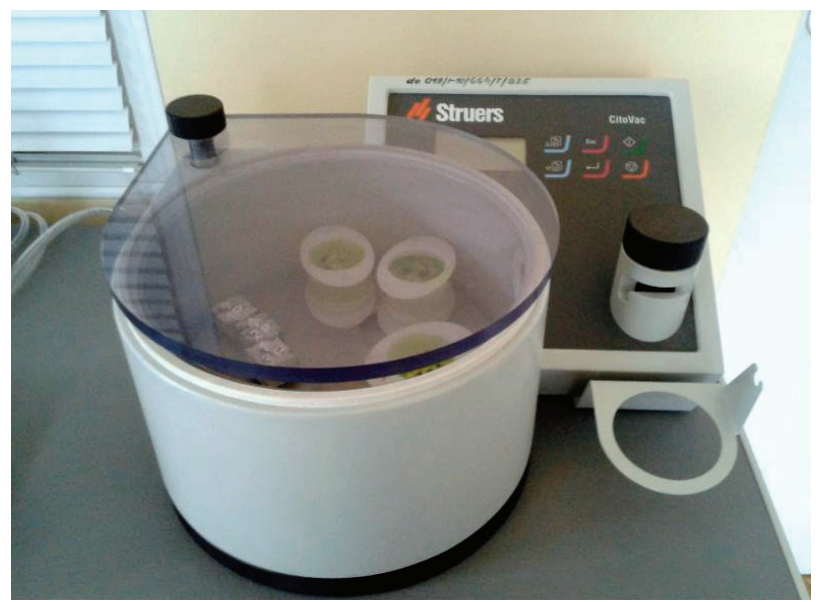

Sample surface preparation was executed with the use of the Struers LaboDoser polishing machine (Fig. 3a) with a semi-automatic diamond suspension dozer (Fig. 3b). Mechanical preparation consists of two processes, namely grinding and polishing, respectively. During the properly performed grinding, the outer damaged layer of the sample is removed. The goal of this stage is to obtain possibly flat surface with the minimal new deformations, which can be relatively easily and fast eliminated during the polishing phase.

The first stage of the grinding is called the initial phase. Its aim is to even the surface of the samples in spite of their original state or the previous treatment. MD-Gekko plate (Fig. 4a) covered with a special foil with high friction coefficient was applied for this purpose. As a result of the next stage precise grinding, a low roughness surface is being acquired which can be improved during polishing. In order to be able to achieve
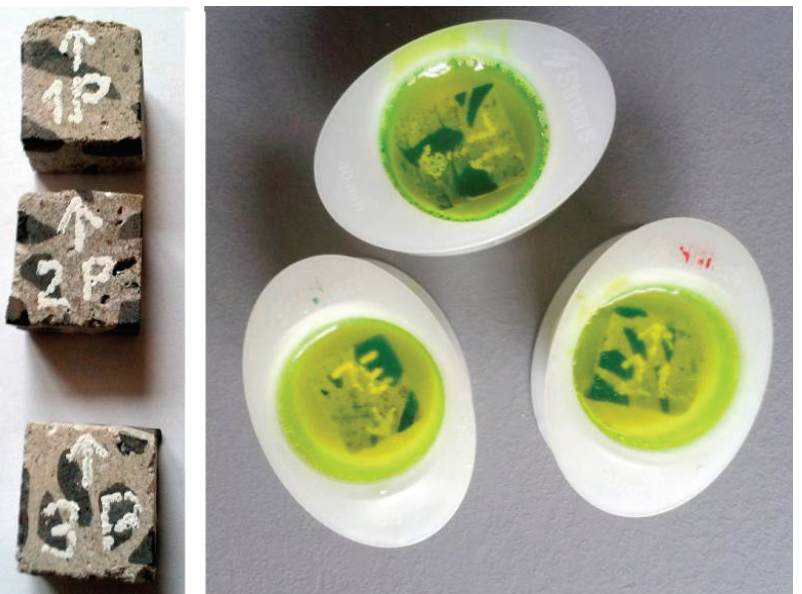

Fig. 2. (a) Vacuum machine for the resin embedding of the samples,

(b) concrete samples cut from the cores, (c) samples in the molds filled with resin
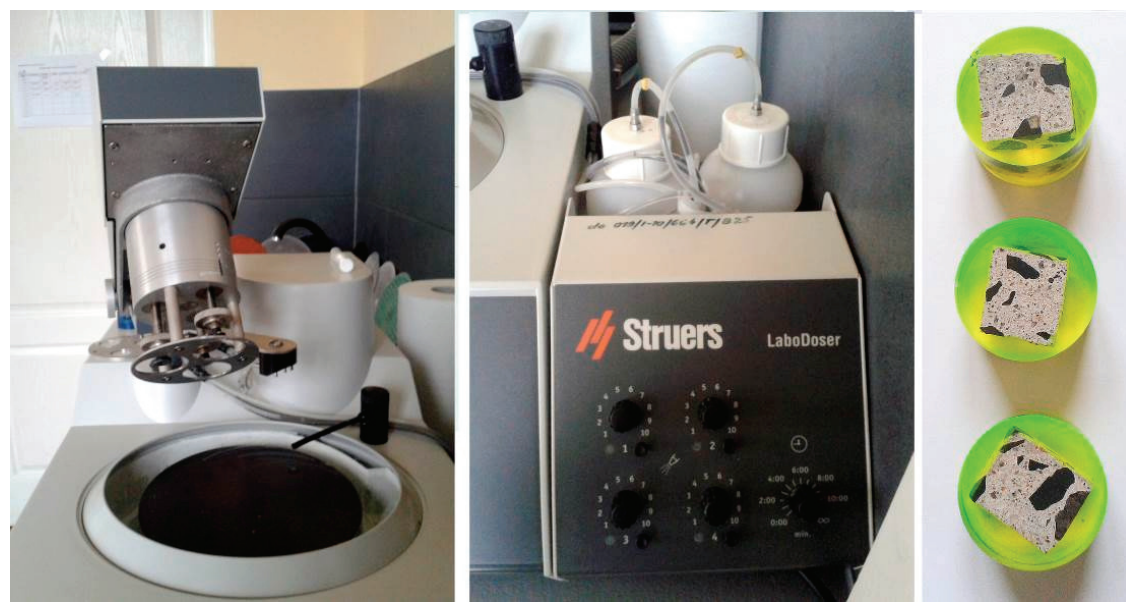

Fig. 3. (a) Polishing machine, (b) diamond suspension dozer, (c) of set polished samples 


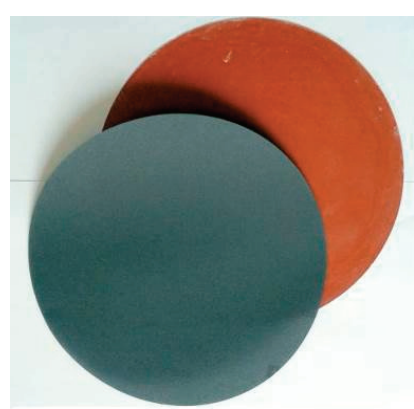

(a)

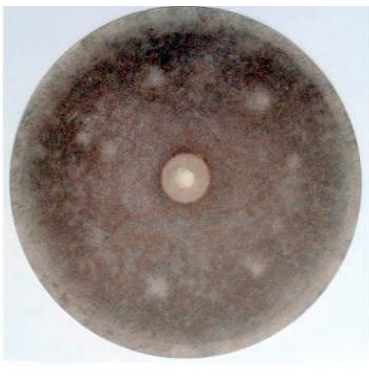

(b)

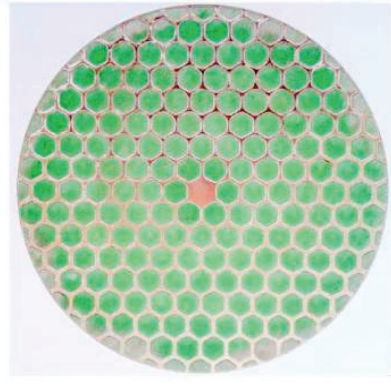

(c)

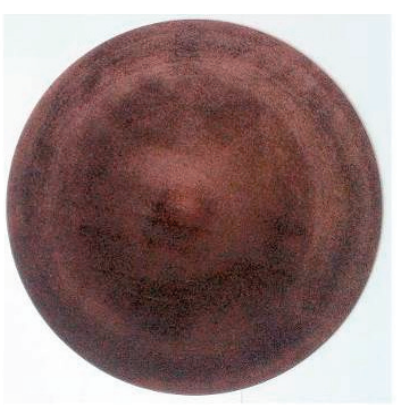

(d)

Fig. 4. Grinding and polishing plates: (a) MD-Gekko, (b) MD-Largo, (c) MDPan, (d) MDNap

this effect, MD-Largo plate (Fig. 4b) was used together with a suspension containing $9 \mu \mathrm{m}$ diamond particles.

Polishing phase aims to remove the deformations and damage induced in the previous operations from the surface. It can be executed in several stages with the use of abrasives with decreasing particle sizes. Again a diamond suspension is being applied in order to obtain a surface with the lowest roughness parameter. For the concrete samples under study, the MDPan (Fig. 4c) and MDNap (Fig. 4d) were used with the suspensions containing 3 and $1 \mu \mathrm{m}$ particles, respectively. A set of polished samples is presented in Fig. 3c.

\section{RESULTS}

The technology of the mature concrete improvement by mineral powder consist in applying the mineral powder directly on the surface of bulk concrete which is in contact with the environment. As a consequence, the rate and the effectiveness of the process are controlled by two phenomena, namely: the migration of the substances into the microstructure of the concrete and the kinetics of the crystallization process. Evaluation of the durability of the crystalline phase should, therefore, take into account the shift in time due to those phenomena. The shift in time is associated with the distance of the material point considered from the surface of mineral powder application. Thus, the classical nanoindentation procedure which consists of a series of measurements on the uniform grid has to be modified in order to take into account the edge effect - the nanoindentation grid has to be parameterized by the distance from the surface of mineral powder application to the location considered within concrete. The nanoindentation testing scheme conducted in the paper is shown in Fig. 5. The tests were performed in "test lines" parallel to the surface where the mineral powder was applied. Initially, the distance of $1 \mathrm{~mm}$ between the consecutive test lines was kept. Within each row, the imprints were made approximately every 30 microns. The aggregate was excluded from the testing procedure due to the fact that the internal crystallization processes occur only in cement matrix. In other words, the nanoindentation imprints were chosen to be made only in cement, based on the images from the

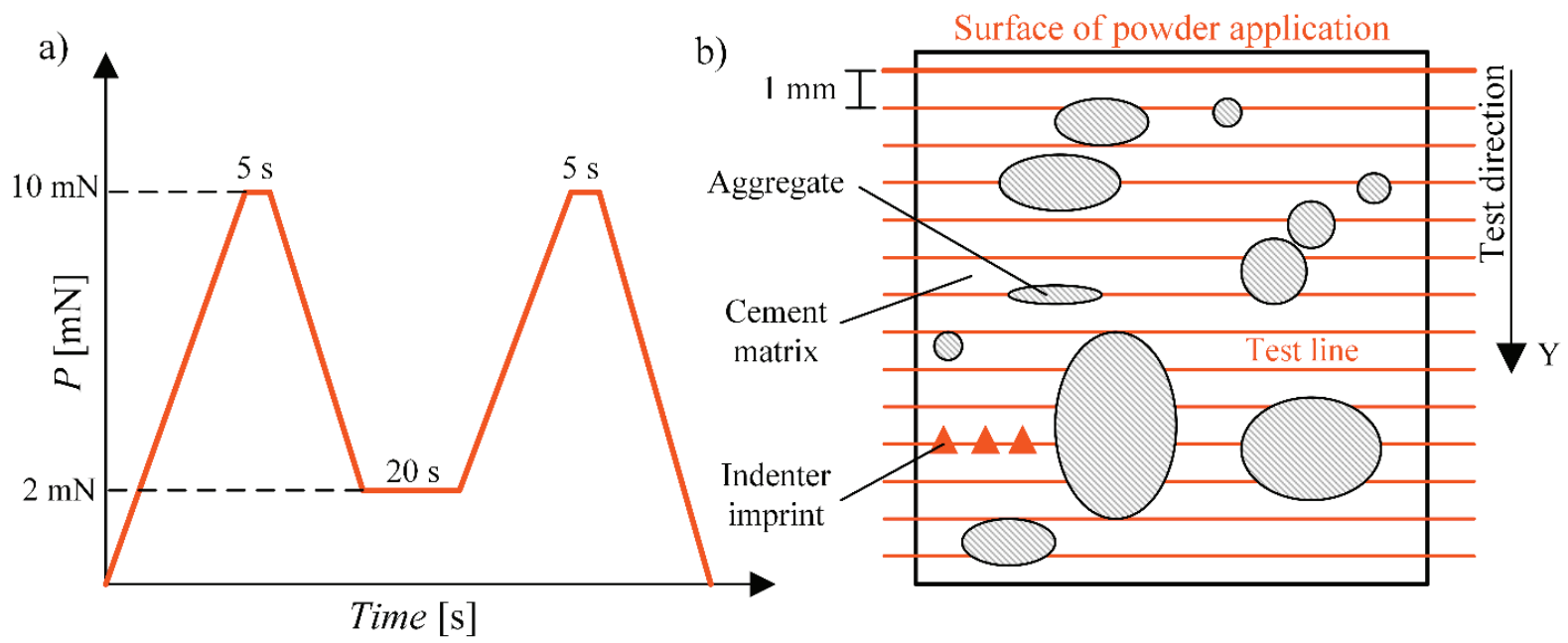

Fig. 5. Nanoindentation testing scheme 
optical microscope. Due to the inhomogeneous character of the material, some difficulties arose concerning the presence of aggregates in the near distance normal to the surface at which the indentation took place, resulting in the high standard deviation of the hardness and the Young Modulus. In addition, it appeared that a great number of tests had to be eliminated due to the unsatisfactory results - the indentation was localized either in epoxy resin or in the aggregate. The results, which could be used to evaluate the estimator of the mean value with assumed $5 \%$ of significance level, corresponding to one line were not sufficient. Therefore, the expectation value was estimated as an average value of the tests from the 5 consecutive lines (Fig. 5b). In other words, the expectation represents the average value from the $5 \mathrm{~mm}$ thickness zone. In addition, during the present study the focus was limited to a $10 \mathrm{~mm}$ distance from the surface.

In order to evaluate the durability, the investigation was performed for the samples with different time of mineral powder exposition, i.e., 1 month, 3 months and 1 year. The results of the sample without any improvement have been used as a reference.

The maximum force applied was $10 \mathrm{mN}$. The loading and unloading phase were repeated twice in order to avoid problems regarding uneven surface and to make sure that there is only elastic deformation when calculating the mechanical parameters (Fig. 5a).

The following figures present the nanoindentation test results, i.e., hardness and Young's modulus corresponding to the reference material and 1 month, 3 months and 1 year after the mineral powder application. For each case, the first figure presents the results of the tests as functions of distance from the surface, where $0 \mathrm{~mm}$ indicates area closest to the surface of the sample (almost at the surface). In the second figure, the corresponding histograms of the results are shown for the zones: almost at the surface, $5 \mathrm{~mm}$ and $10 \mathrm{~mm}$ from the surface. The values in the ranges of $0-2.5 \mathrm{GPa}$ and $0-55 \mathrm{GPa}$, for hardness and the Young Modulus, respectively were only considered (the extreme values were ignored). Figures 6 and 7 correspond to the reference state of the concrete investigated, whereas the next Figs. 8-9, Figs. 10-11, Figs. 12-13 correspond to the samples after 1 month, 3 months and 1 year of exposition. The red line indicates the Gaussian distribution fitted to the data. For the 1 year specimens, the tests covered a longer distance from the surface (Fig. 12), however the histograms were made only for the $10 \mathrm{~mm}$ distance.
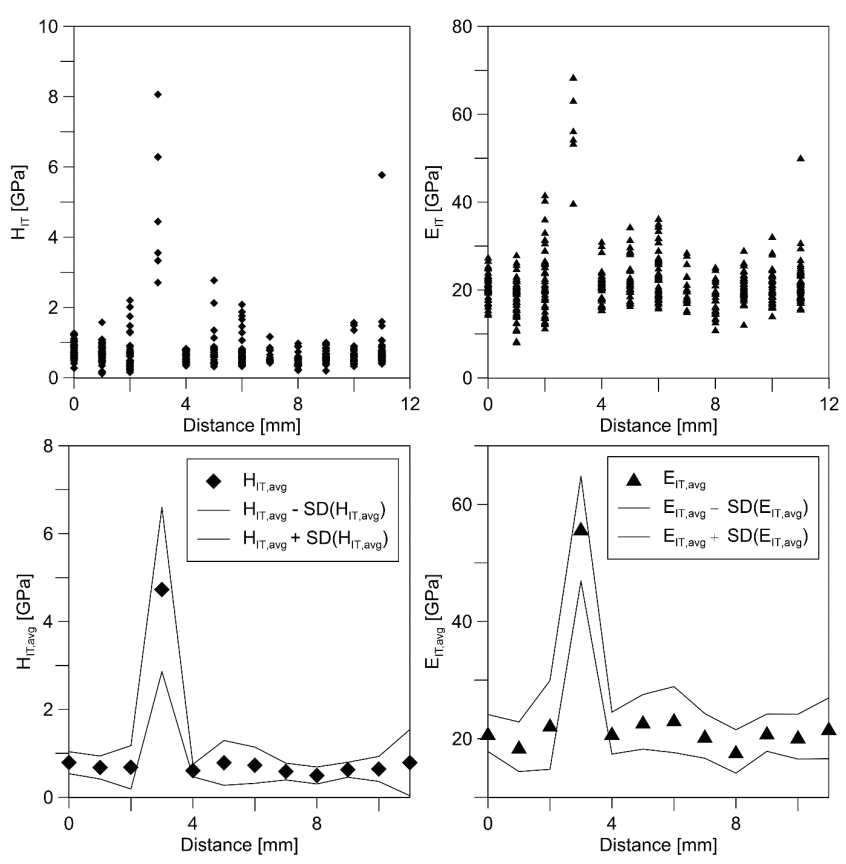

Fig. 6. Values of nanoindentation results: hardness and Young's modulus; reference sample
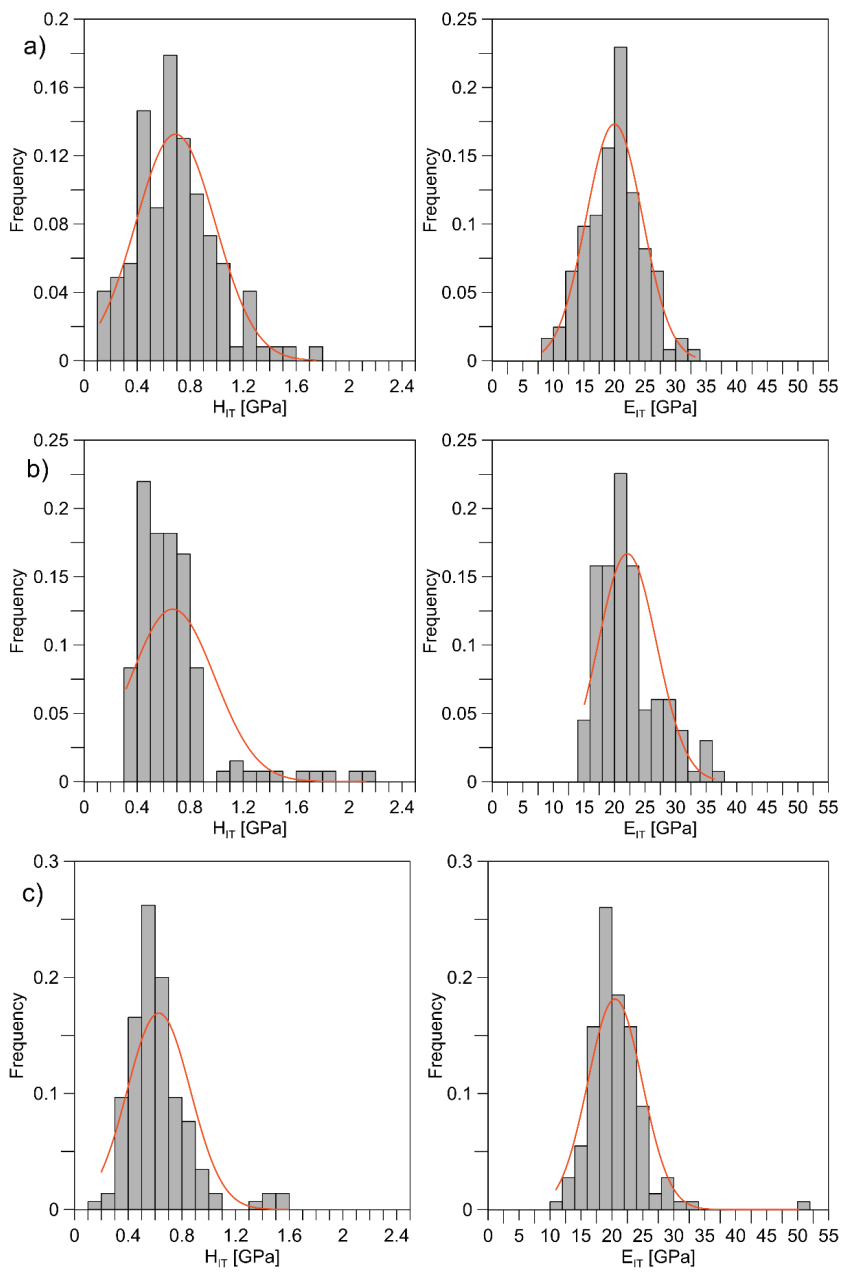

Fig. 7. Histograms of nanoindentation tests: (a) at the surface, (b) $5 \mathrm{~mm}$ from the surface,

(c) $10 \mathrm{~mm}$ from the surface; reference sample 

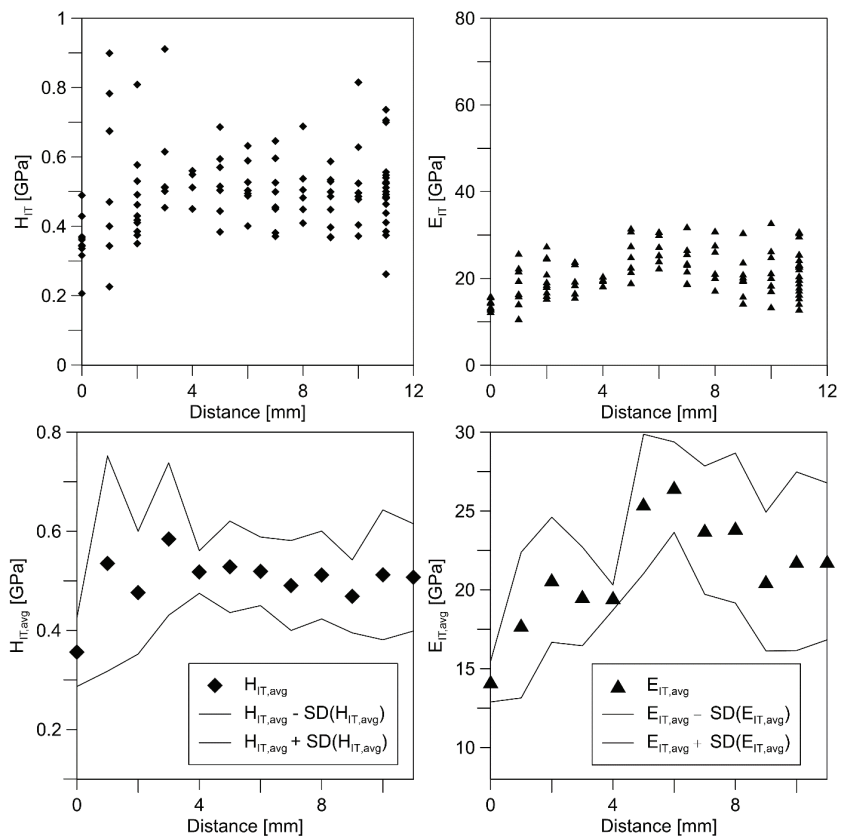

Fig. 8. Values of nanoindentation results: hardness and Young's modulus; 1 month of exposition
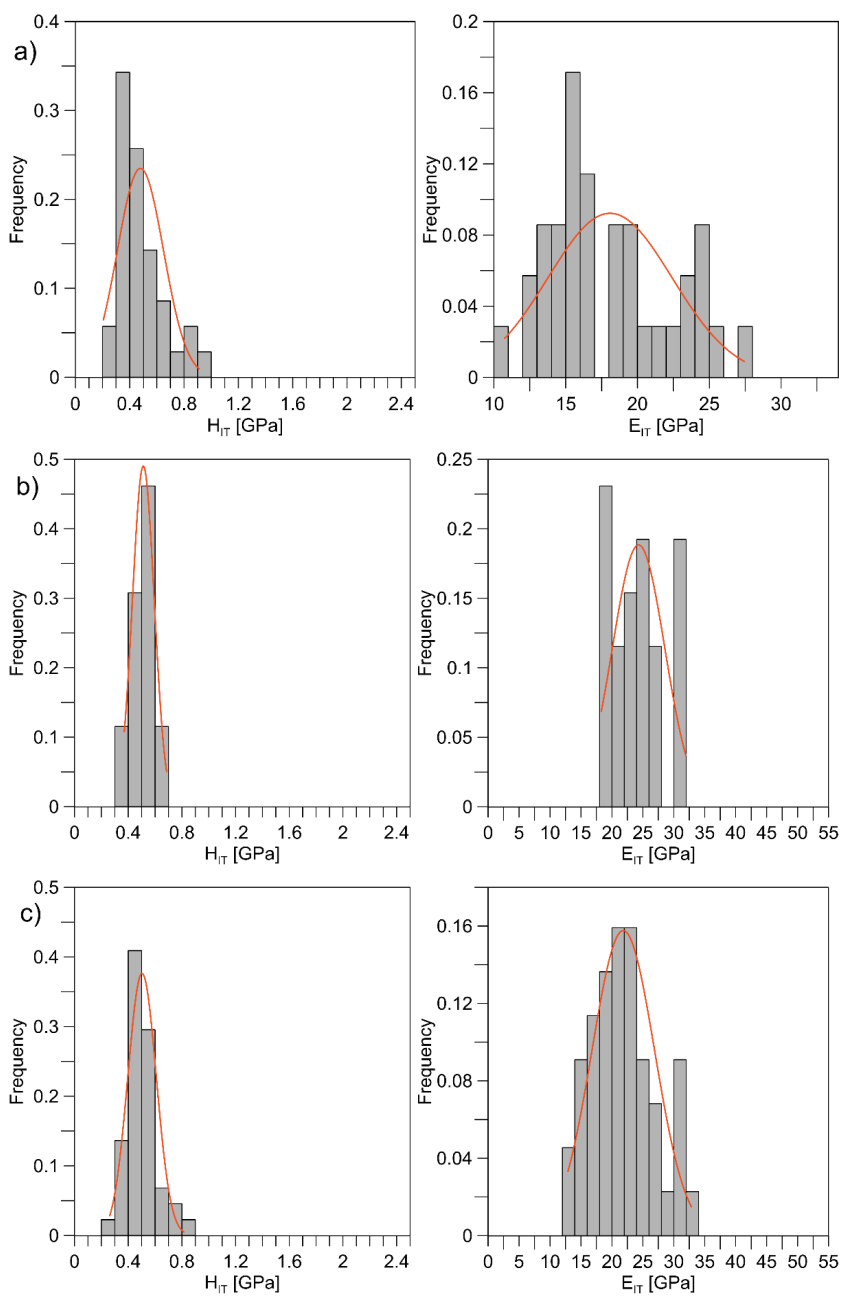

Fig. 9. Histograms of nanoindentation tests:

(a) at the surface, (b) $5 \mathrm{~mm}$ from the surface,

(c) $10 \mathrm{~mm}$ from the surface; 1 month of exposition
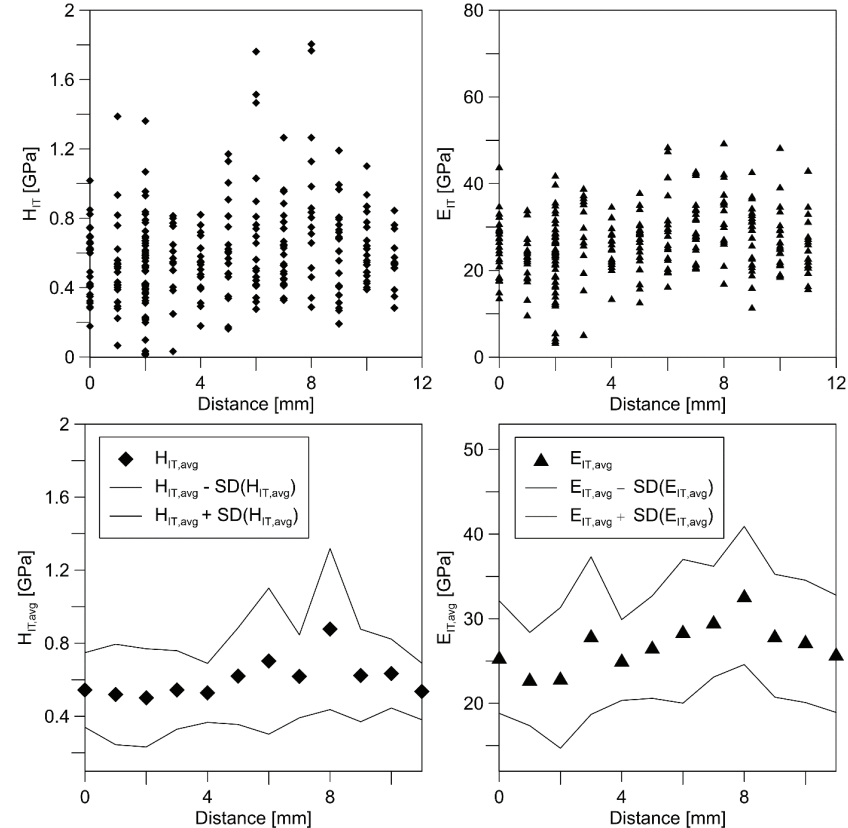

Fig. 10. Values of nanoindentation results: hardness and Young's modulus; 3 months of exposition
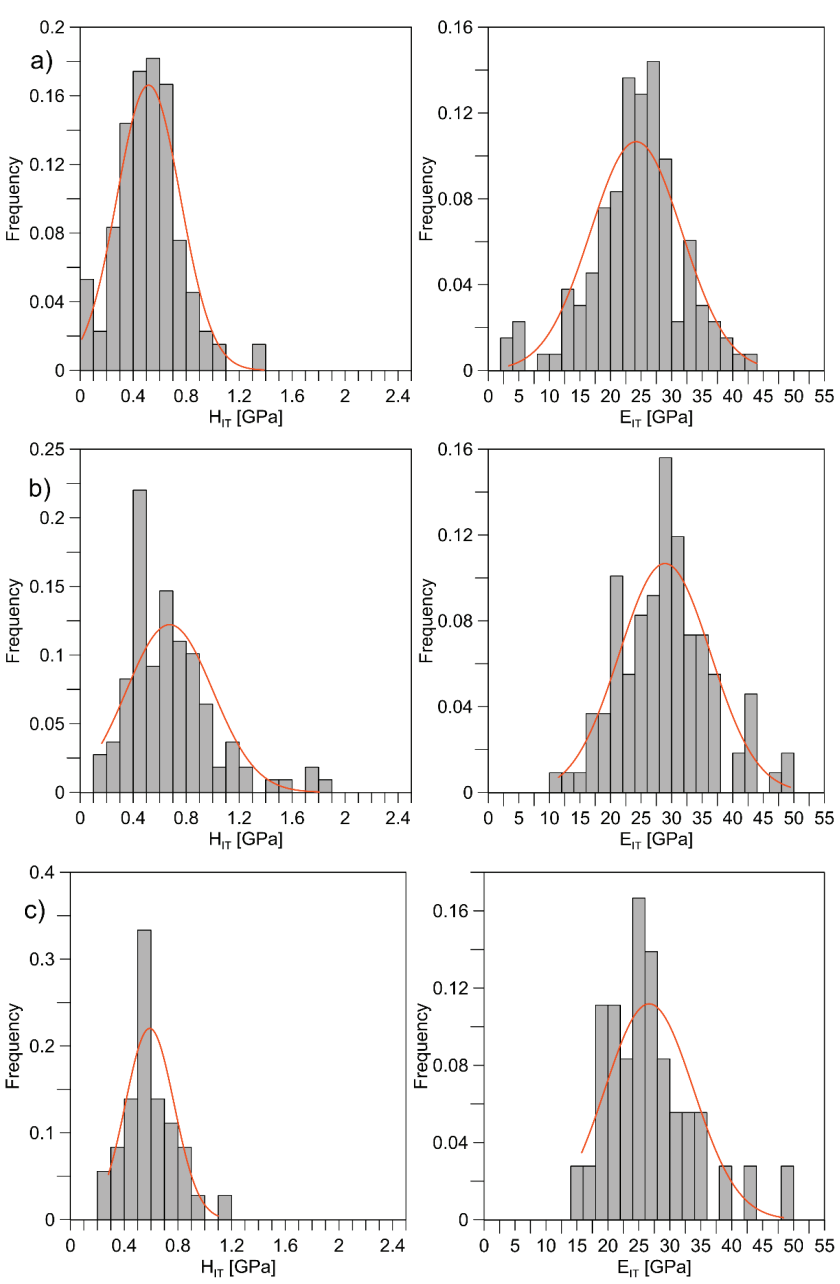

Fig. 11. Histograms of nanoindentation tests:

(a) at the surface, (b) $5 \mathrm{~mm}$ from the surface,

(c) $10 \mathrm{~mm}$ from the surface; 3 months of exposition 

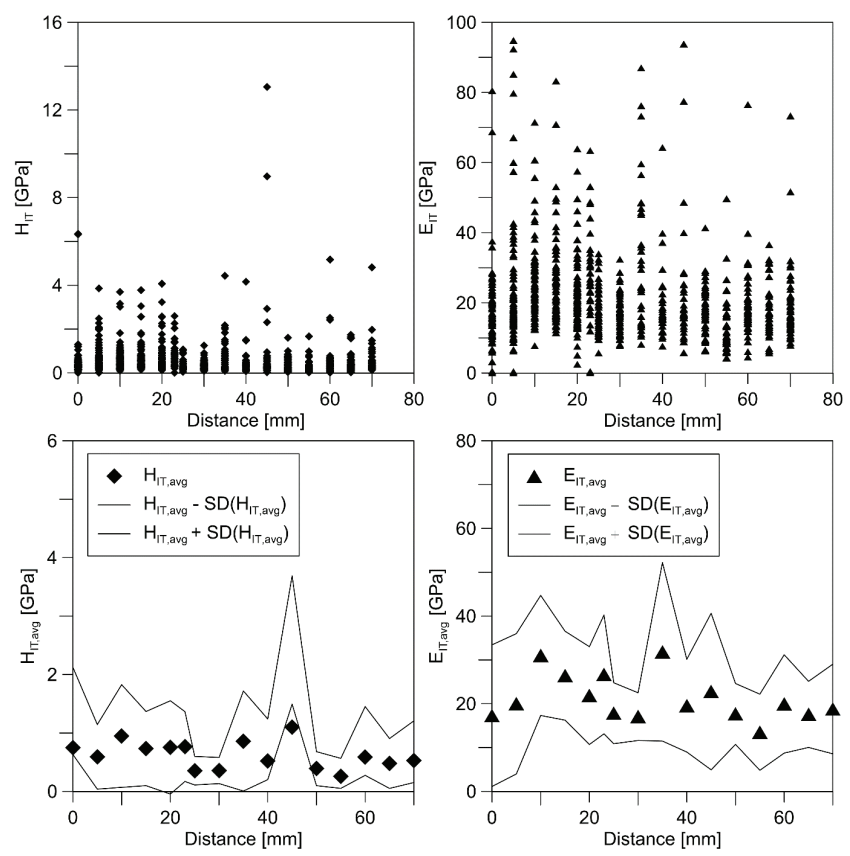

Fig. 12. Values of nanoindentation results: hardness and Young's modulus; 1 year of exposition
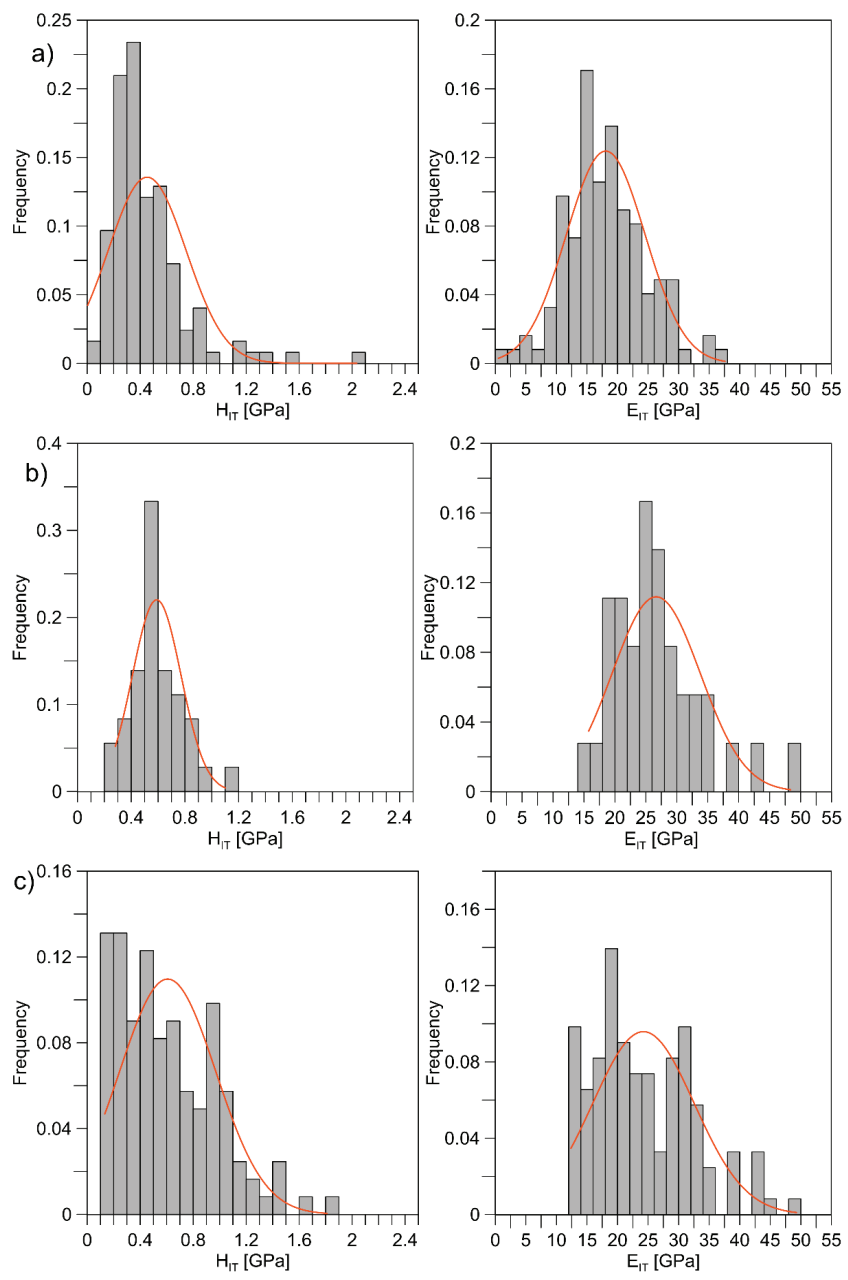

Fig. 13. Histograms of nanoindentation tests: (a) at the surface, (b) $5 \mathrm{~mm}$ from the surface,

(c) $10 \mathrm{~mm}$ from the surface; 1 year of exposition
The evaluation of the durability of the crystalline phase consists in comparative analysis of the results obtained for different exposition times to mineral powder. In Figs. 14, a comparison of the nanoindentation results histograms of hardness and Young's modulus for the reference sample, 1 month, 3 months and 1 year after mineral powder application is presented. Considering the histograms, the relative movement of the Gaussian probability density function fitted to the data is the objective measure of the concrete improvement effectiveness. If this curve moves to the right with exposition time, it proves usefulness of the mineral powder as the improvement material. Otherwise, it indicates the softening effect of the modified concrete microstructure. Careful investigation of the plots presented in Fig. 14 suggests the following scenario has taken place in the material examined. During the first 3 months the mineral powder improves the mechanical properties of the microstructure - the Gaussian PDF moves to the right. The longer exposition time results in successive deterioration of the mechanical properties of the material under study.
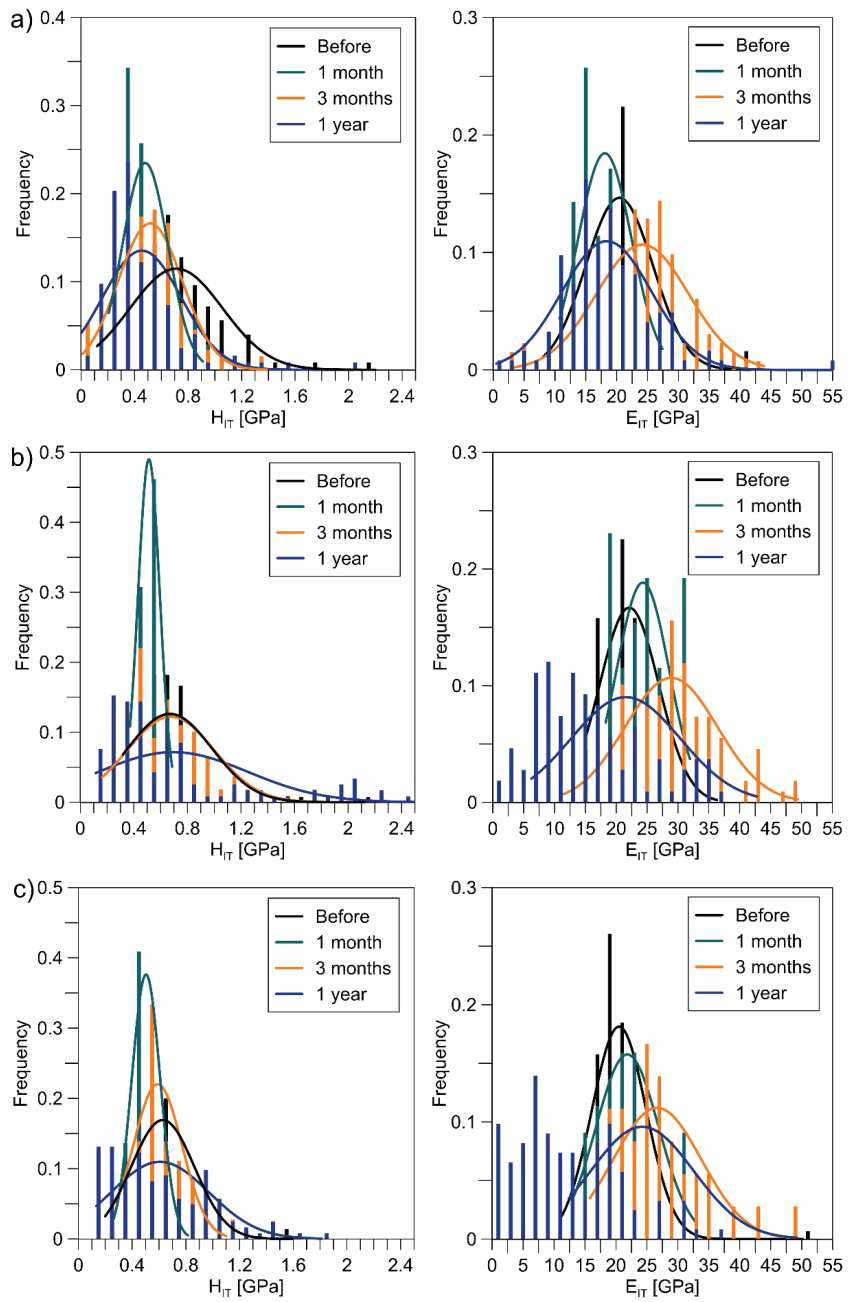

Fig. 14. Comparison of the nanoindentation tests histograms: (a) at the surface, (b) $5 \mathrm{~mm}$ from the surface, (c) $10 \mathrm{~mm}$ from the surface 

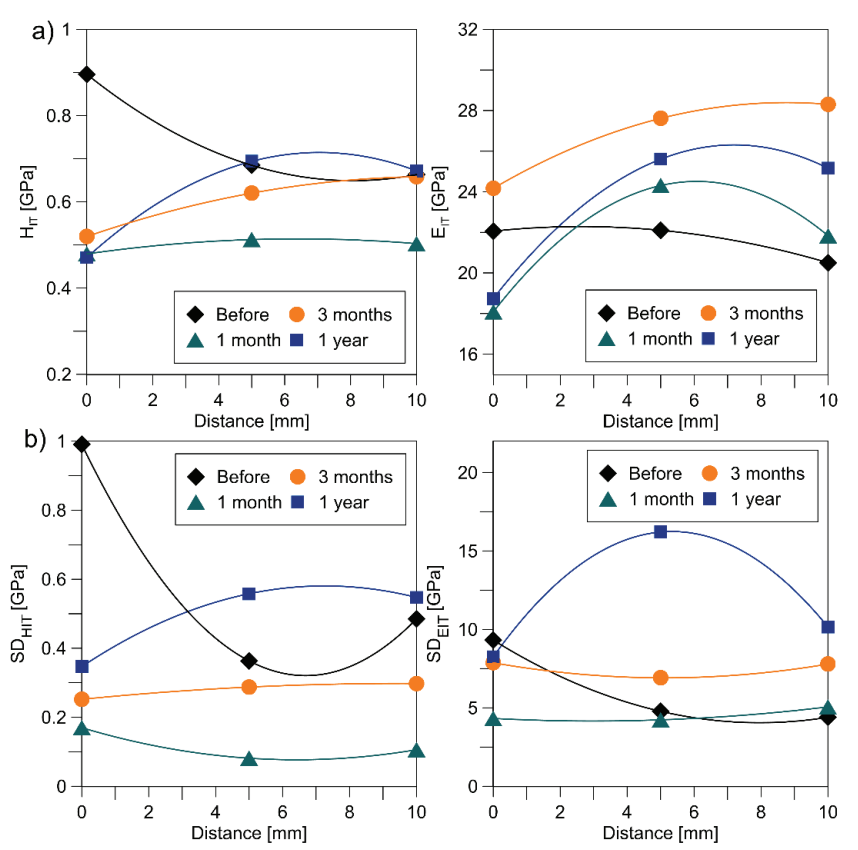

Fig. 15. (a) Mean values of hardness and Young's modulus, (b) the standard deviation of hardness and Young's modulus as functions of the distance from the exposition surface for different exposition times

A comparison of the mean values of mechanical parameters, namely hardness and the Young's modulus, is presented in Fig. 15a. Figure 15b shows a standard deviation of the average values as a function of distance from the surface of mineral powder application. In Fig. 16, the evolution of the mechanical parameters in exposition time is demonstrated at surface, $5 \mathrm{~mm}$ and $10 \mathrm{~mm}$ from the surface of concrete modification.
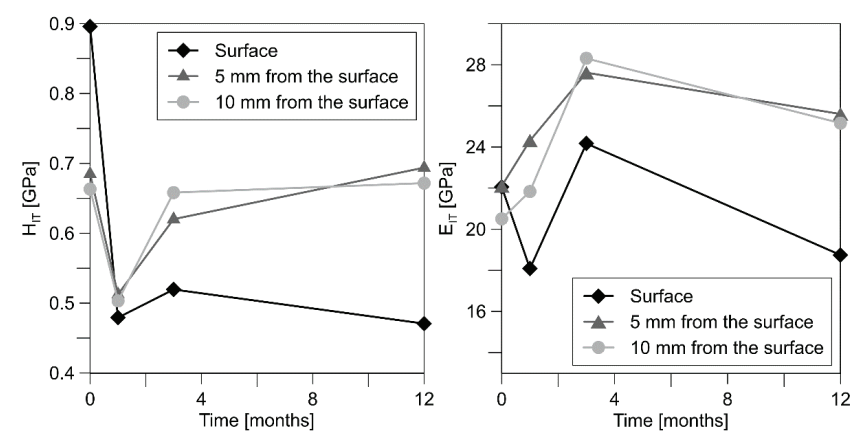

Fig. 16. Evolution of hardness and Young's modulus with exposition time

Taking into account the aforementioned results, it can be seen that there is an evident improvement of the concrete mechanical parameters 3 months after mineral powder application. 1 year after ICT application, destructive changes in the concrete microstructure are visible. Mechanical parameters are similar or even worse than the initial ones, before the mineral powder application. The kinetics of the "secondary" degradation (the "primary" one was due to the corrosion) is strongly dependent on the distance from the modification surface - the closer to the surface, the faster the deterioration occurs. The results obtained from the nanoindentation tests suggest that the ICT mineral powder is only "active" for several months - further strengthening of concrete requires, at least repetitive application of the aforementioned substance.

\section{SUMMARY}

In this paper, the durability evaluation of the Internal Crystallization Technology was performed by means of nanoindentation technique. The study referred to a reallife engineering problem, namely the material under investigation was deteriorated concrete extracted from the concrete lining in a deep mine shaft. The samples were tested in reference state, 1 month, 3 months and 1 year after concrete modification. The hardness as well as Young's modulus of the material were evaluated. The quantitative analysis consisted of comparison of the histograms, average values and standard deviations of the concrete mechanical parameters. In addition, evolution of the microstructure as a function of exposition time was investigated.

The microstructural nanoindentation tests clearly indicate that the Internal Crystallization mineral powders have their own "life time" of approximately several months. The initial improvement phase is followed by the decrease in mechanical parameters suggesting that in order to maintain the "strengthening" effect, the repetitive application of the powder is necessary. What might be found worrying is the fact that the reduction of parameters might be substantial resulting in the material in a worse state than before the ICT application. Further research is needed in order to thoroughly investigate and confirm this phenomenon.

\section{REFERENCES}

Bовко C.P., 2008, Assessing the mechanical microstructure of shale by nanoindentation: The link between mineral composition and mechanical properties, Doctoral dissertation, Massachusetts Institute of Technology.

BOUSSINESQ J., 1885, Applications des potentiels h l'rtude de l'rquilibre et du mouvement des solides 61 astiques, Gauthier-Villars.

Constantinides G., Ulm F.J., VAn Vliet K., 2003, On the use of nanoindentation for cementitious materials, Materials and Structures, 36(3), 191-196.

Constantinides G., Chandran K.R., Ulm F.J., VAN Vliet K.J., 2006, Grid indentation analysis of composite microstructure 
and mechanics: principles and validation, Materials Science and Engineering: A, 430(1), 189-202.

DoERnER M.F., NIX W.D., 1986, A method for interpreting the data from depth-sensing indentation instruments, Journal of Materials Research, 1(04), 601-609.

Fan Z., Swadener J.G., Rho J.Y., Roy M.E., Pharr G.M., 2002, Anisotropic properties of human tibial cortical bone as measured by nanoindentation. Journal of Orthopaedic Research, 20(4), 806-810.

Krakowiak K.J., Lourenço P.B., Ulm F.J., 2011, Multitechnique investigation of extruded clay brick microstructure, Journal of the American Ceramic Society, 94(9), 3012-3022.

KRAKOWIAK K.J., 2011, Assessment of the mechanical microstructure of masonry clay brick by nanoindentation.

Mondal P., Shah S., Marks L., Gaitero J., 2010, Comparative study of the effects of microsilica and nanosilica in concrete, Transportation Research Record: Journal of the Transportation Research Board, 2141, 6-9.

NĚMEČEK J., KOPECKÝ L., BitTNAR Z., 2005, Size effect in nanoindentation of cement paste, [in:] Proceedings of the International Conference on Applications of Nanotechnology in Concrete Design, Eds. Dhir, RK, 47-53.

NeŽERKA V., NĚMEČEK J., SlížKovÁ Z., TesáRek P., 2015, Investigation of crushed brick-matrix interface in lime-based ancient mortar by microscopy and nanoindentation, Cement and Concrete Composites, 55, 122-128.

Oliver W.C., Pharr G.M., 2004, Measurement of hardness and elastic modulus by instrumented indentation: Advances in understanding and refinements to methodology, Journal of Materials Research, 19(01), 3-20.

PhARr G.M., OlIVER W.C., 1992, Measurement of thin film mechanical properties using nanoindentation, Mrs Bulletin, 17(07), 28-33.
Rho J.Y., Tsui T.Y., Pharr G.M., 1997, Elastic properties of human cortical and trabecular lamellar bone measured by nanoindentation, Biomaterials, 18(20), 1325-1330.

Rho J.Y., Zioupos P., Currey J.D., Pharr G.M., 2002, Microstructural elasticity and regional heterogeneity in human femoral bone of various ages examined by nano-indentation, Journal of Biomechanics, 35(2), 189-198.

Sorelli L., Constantinides G., Ulm F.J., Toutlemonde F., 2008, The nano-mechanical signature of ultra-high performance concrete by statistical nanoindentation techniques, Cement and Concrete Research, 38(12), 1447-1456.

Syed Asif S.A., Pethica J.B., 1997, Nanoindentation creep of single-crystal tungsten and gallium arsenide, Philosophical Magazine A, 76(6), 1105-1118.

TAREFDER R., FAISAL H., 2013, Nanoindentation characterization of asphalt concrete aging, Journal of Nanomechanics and Micromechanics, 4(1), A4013003.

Ulm F.J., VAndamme M., Bobko C., Alberto Ortega J., Tai K., ORTIZ C., 2007, Statistical indentation techniques for hydrated nanocomposites: concrete, bone, and shale, Journal of the American Ceramic Society, 90(9), 2677-2692.

VANDAMME M., 2008, The nanogranular origin of concrete creep: a nanoindentation investigation of microstructure and fundamental properties of calcium-silicate-hydrates, Doctoral dissertation, Massachusetts Institute of Technology.

Xiao J., Li W., Sun Z., Lange D.A., Shah S.P., 2013, Properties of interfacial transition zones in recycled aggregate concrete tested by nanoindentation, Cement and Concrete Composites, 37, 276-292.

ZADEH V.Z., BOBKO C.P., 2013, Nanoscale mechanical properties of concrete containing blast furnace slag and fly ash before and after thermal damage, Cement and Concrete Composites, 37, 215-221. 